\section{West London first-episode study of schizophrenia}

\section{Clinical correlates of duration of untreated psychosis}

THOMAS R. E. BARNES, S. B. HUTTON, M. J. CHAPMAN, S. MUTSATSA, B. K. PURI and EILEEN M. JOYCE

\begin{abstract}
Background Studies in schizophrenia suggest that a longer initial period of untreated illness is associated with a poorer clinical outcome.
\end{abstract}

Aims To determine whether, in firstepisode schizophrenia, a longer duration of untreated psychosis (DUP) or of untreated illness (DUI) (DUP plus any prodrome) is associated with clinical variables that could mediate a poor prognosis.

Method Clinical, social, neuropsychological and oculomotor function data on 53 patients with firstepisode schizophrenia were related to the DUP and DUI.

Results Comparing short and long DUP groups split around the median showed no statistically significant differences (except age); patients in the latter group tended to perform worse on an executive attentional set-shifting task, and were more likely to be unemployed, and living alone or homeless.

Conclusions There was little evidence of any association between either DUP or DUI and progressive deterioration in the schizophrenic illness or the development of resistance to initial drug treatment.

Social variables that augur a poor

prognosis may be associated with delayed presentation of schizophrenia to

psychiatric services.

Declaration of interest Supported by the WellcomeTrust.
The findings of first-episode studies of schizophrenia suggest that the longer psychosis proceeds unchecked before treatment, the poorer the response to antipsychotic medication and the poorer the outcome in terms of symptoms, function and relapse (Johnstone et al, 1990; Loebel et al, 1992). One explanation is that the illness gets gradually worse during the untreated period. This might indicate an active morbid process, which could be ameliorated with antipsychotic drugs (Waddington et al, 1998); or, alternatively, the social and psychological disruption of a long period of untreated illness might contribute to morbidity (McGlashan, 1998). In either case, early intervention might have some secondary preventive effect.

However, other possible explanations call into doubt the potential value of early treatment. For example, a longer period between the onset of illness and antipsychotic treatment may be related to demographic, social or clinical factors which delay identification of the illness as well as contributing to a poor prognosis (Verdoux et al, 1998). Alternatively, schizophrenic illnesses with an intrinsically poor prognosis may be less likely to be noticed early because of the patients' impaired insight and refusal of treatment, or because the symptom and behaviour profile is not subjectively distressing or particularly evident in a social context.

In our prospective study of first-episode schizophrenia we examined whether the duration of psychotic illness prior to presentation to psychiatric services was related to the severity or deterioration of the illness. We used the following measures: the severity and symptom profile of the illness at first presentation; the pattern and severity of neurocognitive deficit, including measures of oculomotor functioning; the response to treatment during the first hospital admission; and social variables related to employment and accommodation.

\section{METHOD}

\section{Patients}

All patients had been recruited into a prospective clinical and neurobiological study of first-episode schizophrenia in West London (Hutton et al, 1998a), the vast majority being seen at the time of their first admission to hospital. The patients eligible for this study were aged between 16 and 50 years. In each case a DSM-IV diagnosis of schizophrenia (American Psychiatric Association, 1994) had been confirmed at subsequent diagnostic review by two experienced clinicians (E.M.J. and T.R.E.B.). For each patient, the diagnosis was critically reviewed at a formal consensus meeting, involving the clinical investigators, within 3 months of entering the study. The catchment area included some inner London areas and a more suburban, outer London area. Ethical approval was obtained from the relevant local Ethics Committees.

\section{Assessments}

Mental state assessment

At initial interview, the assessment scales used included the Comprehensive Psychopathological Rating Scale (CPRS; Asberg et al, 1978), the Clinical Global Impression (CGI), the Scale for the Assessment of Positive Symptoms (SAPS; Andreasen, 1990) and Scale for the Assessment of Negative Symptoms (SANS; Andreasen, 1990).

Scores for the three symptom-derived syndromes of schizophrenia - reality distortion, disorganisation and psychomotor poverty (Liddle \& Barnes, 1990)-were calculated for each patient by adding the global sub-scale scores on the SAPS and SANS pertaining to each factor, and dividing by the maximum score possible to give a value for each factor of between zero and one (Gur et al, 1991).

\section{Neuropsychological function}

For the majority of patients $(n=42)$, premorbid IQ was estimated with the National Adult Reading Test (NART, revised version; Nelson, 1991). Of the remaining 11 patients, six did not have English as a first language and five reported dyslexia. Current full-scale IQ was assessed in 36 patients using a shortened form of the revised Wechsler Adult Intelligence Scale (WAIS-R; Wechsler, 1981). Time constraints during the neuropsychology testing sessions meant that the remaining 16 
patients did not complete a sufficient number of sub-tests of the WAIS to allow a full-scale IQ to be calculated.

Neurocognitive function was assessed using memory and executive function tests from the computerised Cambridge Automated Neuropsychological Test Battery (CANTAB; Sahakian \& Owen, 1992). These tests were run on an IBM-compatible personal computer with a touch-sensitive screen. The memory tests were spatial span and spatial and pattern recognition memory, while executive function was tested with a planning task (modified Tower of London test; Shallice, 1982) and attentional set-shifting task. For a description of the nature of these tests, the performance measures used and how the test scores are derived, see Hutton et al (1998a).

\section{Oculomotor function}

Both saccadic and smooth-pursuit eye movements were assessed, as described in detail elsewhere (Hutton et al, 1998b). The measures used in the present paper were antisaccade errors (the number of times subjects failed to inhibit a reflexive saccade towards a target) and smooth pursuit velocity gain (the ratio of the eye velocity to target velocity).

\section{Clinical information}

To collect basic demographic and historical data, particularly relating to accommodation and employment in the year preceding admission, and details of all medication received, a clinical data sheet was completed for each patient, 6 weeks after they entered the study. Based on these data, on the medical records and, in some cases, on interview with members of the relevant clinical team, the response to antipsychotic medication during the initial hospital admission was assessed by investigators (E.M.J. and T.R.E.B.) blind to the baseline ratings of mental state and results of the neuropsychological tests. The response score reflected a patient's degree of improvement in symptoms and personal and social functioning, according to the scale developed by Brenner $\mathrm{et} \mathrm{al} \mathrm{(1990),} \mathrm{a} \mathrm{7-point} \mathrm{scale} \mathrm{going}$ from clinical remission (1) to severely refractory (7).

\section{Duration of untreated illness}

The duration of untreated illness was established for each patient by reviewing the relevant information in the case notes, and questioning the patient and relatives and/ or carers. A modified questionnaire (Loebel et al, 1992) was used, relating to the date of onset of any personality change or disturbed behaviour that became persistent (prodromal symptoms), and the onset of positive psychotic symptoms (Lieberman et al, 1993). Two variables were generated: the duration of untreated psychosis (DUP) (i.e., the time from onset of psychotic symptoms to first treatment with antipsychotic medication), and the total duration of untreated illness (DUI) (the duration of untreated psychosis plus any period of prodromal symptoms).

\section{Data analysis}

Two separate planned analyses were performed, one for DUP and one for DUI. In each case, the median duration was calculated and used to split the sample into two groups: short and long duration. Independent $t$-tests were then performed on the various neurocognitive and clinical variables, and $\chi^{2}$ tests were used for the social variables.

\section{RESULTS}

\section{Duration of untreated psychosis}

Adequate data were available on all 53 patients. The median DUP was 26 weeks (mean $=59$, s.d. $=93$ ), while the median DUI was 104 weeks (mean=173, s.d. $=265$ ). For each patient in the sample, the DUP and

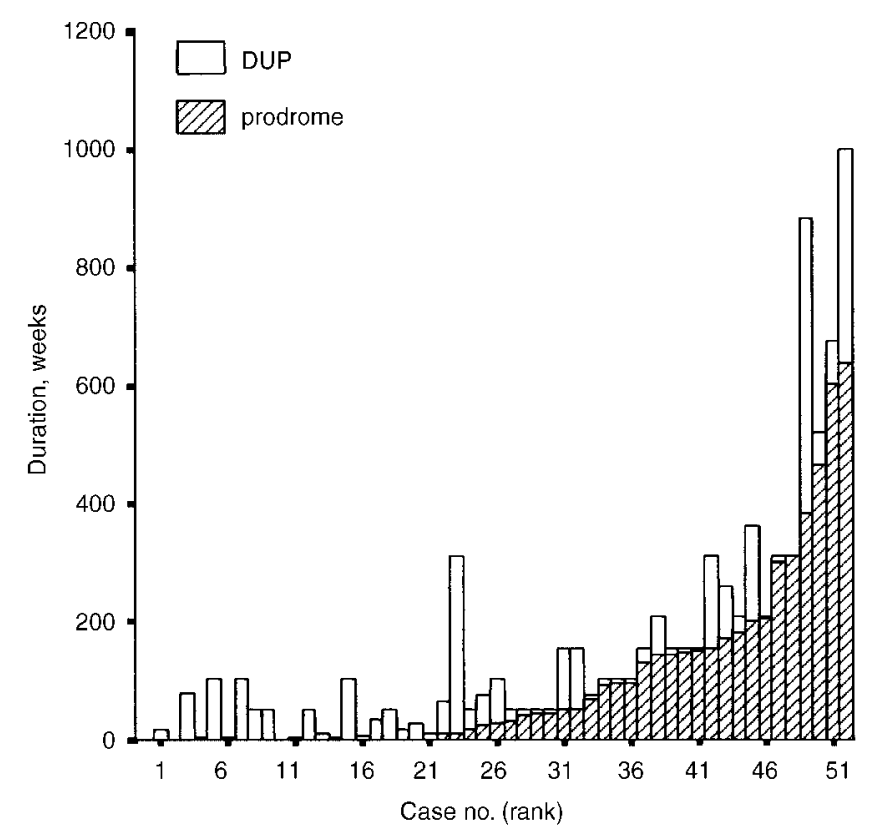

Fig. I Duration of untreated psychosis (DUP) and duration of any preceding prodrome for each patient in the sample $(n=52)$. the duration of any preceding prodromal period are illustrated in Fig. 1 (excluding one outlier: a woman with a 31-year history of anorexia nervosa and agoraphobia preceding the onset of psychotic symptoms). For the total sample, there was no significant correlation between DUP and the length of the prodrome period.

Table 1 provides information on the basic demographic and clinical characteristics of the total sample and the two subgroups, split around the median value for DUP. No significant differences between the two groups emerged on the IQ variables or mean scores for the three clinical syndromes. The mean age of the group with the longer mean DUP was significantly higher. However, the mean age of onset of illness did not differ significantly between the short and long DUP groups, although the figure was marginally higher in the latter.

With regard to the neurocognitive measures, the only differences that emerged concerned performance on the attentional set-shifting task of the CANTAB, which was worse in the longer DUP group, at a trend level of significance. Of those patients with a DUP of less than 26 weeks, $20 \%$ failed to complete this task, compared with $41 \%$ of those with a DUP of 26 weeks or more $\left(\chi^{2}=2.6, P=0.1\right)$, while the mean total errors across the whole task (both intradimensional and extradimensional shift stages) were 29.2 and 43.1 for the two groups respectively $\left(\chi^{2}=1.8, P=0.07\right)$. The 
Table I Clinical characteristics of the total sample, and two subgroups split around the median duration of untreated psychosis (DUP)

\begin{tabular}{|c|c|c|c|c|}
\hline & \multirow{2}{*}{$\begin{array}{l}\text { Total sample } \\
\qquad(n=53)\end{array}$} & \multicolumn{2}{|c|}{ Duration of untreated psychosis } & \multirow{2}{*}{$\begin{array}{c}t \text {-test } \\
P\end{array}$} \\
\hline & & \multicolumn{2}{|c|}{$<26$ weeks $(n=26) \geqslant 26$ weeks $(n=27)$} & \\
\hline Mean age, years (s.d.) & $26.1(7.8)$ & $23.9(7.2)$ & $28.2(7.9)$ & 0.046 \\
\hline Mean age of onset, years (s.d.) & $25 \quad(7.4)$ & $23.7(7.2)$ & $26.1(7.5)$ & NS \\
\hline Male/female & $42 / 11$ & $23 / 3$ & $19 / 8$ & NS \\
\hline $\begin{array}{l}\text { Mean duration of untreated } \\
\text { psychosis, weeks (s.d.) }\end{array}$ & $59(92.8)$ & $8.5(6.1)$ & $107.6(110.5)$ & $<0.001$ \\
\hline $\begin{array}{l}\text { Mean length of prodrome } \\
\text { period, weeks (s.d.) }\end{array}$ & II3.5 (232) & $67(79)$ & $157(310)$ & NS \\
\hline Estimate of IQ using NART' & $100.7(10.5)$ & $101.9(9.6)$ & $99.6(I I .4)$ & NS \\
\hline Full-scale IQ (WAIS-R $)^{2}$ & $96.5(15)$ & $94.1(13.2)$ & $98.6(16.5)$ & NS \\
\hline \multicolumn{5}{|l|}{ Syndrome scores: mean (s.d.) } \\
\hline psychomotor poverty & $0.36(0.25)$ & $0.38(0.26)$ & $0.34(0.24)$ & NS \\
\hline reality distortion & $0.73(0.26)$ & $0.76(0.24)$ & $0.70(0.27)$ & NS \\
\hline disorganisation & $0.35(0.25)$ & $0.36(0.25)$ & $0.34(0.24)$ & NS \\
\hline \multicolumn{5}{|l|}{ Accommodation: $n(\%)$} \\
\hline \multicolumn{5}{|l|}{ Living with family member } \\
\hline or partner & $39(73)$ & $22(85)$ & $17(63)$ & - \\
\hline Living alone & II (2I) & $3(I I)$ & $8(30)$ & - \\
\hline Homeless & $3(6)$ & I (4) & $2(7)$ & - \\
\hline \multicolumn{5}{|l|}{ Employment status: $n$ (\%) } \\
\hline Employed & $7(13)$ & $4(15)$ & $3(I I)$ & - \\
\hline Unemployed & $35(66)$ & $14(54)$ & $21(78)$ & - \\
\hline Student & II (2I) & $8(3 I)$ & $3(I I)$ & - \\
\hline
\end{tabular}

I. Total sample $n=42$; DUP $<26$ weeks: $n=20$; DUP $\geqslant 26$ weeks: $n=22$.

2. Total sample: $n=36$; DUP $<26$ weeks: $n=17$; DUP $\geqslant 26$ weeks: $n=19$.

NART, National Adult Reading Test, revised version; WAIS-R, revised Wechsler Adult Intelligence Scale. same comparison of the short and long DUI groups, split around the median, yielded very few significant differences. There were no significant differences between the two DUI groups on any of the CANTAB tests.

The long DUI group had a significantly older mean age and higher current full-scale IQ (as well as a higher NART-estimated IQ) at a trend level (Table 2). For each patient in the sample, the full-scale WAIS IQ figure was subtracted from the NART IQ to generate an estimate of possible intellectual decline. On this measure, there was no significant difference between the short DUP (mean $=5.4$, s.d. $=12.4)$ and long DUP $($ mean $=1.8$, s.d. $=12.3)$ groups $(t=0.79$, d.f. $=28, P=0.44)$ or between the short DUI (mean $=6.2$, s.d. $=13.6$ ) and long DUI $($ mean $=1.4$, s.d. $=11.0)$ groups $(t=1.09$, d.f. $=28, P=0.29$ )
Table 2 Revised National Adult Reading Test (NART) and full-scale IQ for the two subgroups split around the median duration of untreated illness (DUI)

\begin{tabular}{|c|c|c|c|}
\hline & \multicolumn{2}{|c|}{ Duration of untreated illness } & \multirow{2}{*}{$\begin{array}{c}t \text {-test } \\
P\end{array}$} \\
\hline & $\leqslant 104$ weeks & $>104$ weeks & \\
\hline DUI, weeks, mean (s.d.)' & $35(26.5)$ & $30 I(319)$ & $<0.001$ \\
\hline Estimate of IQ using NART, mean (s.d.) $)^{2}$ & $97.7(10)$ & $103.2(10.5)$ & 0.09 \\
\hline Full-scale IQ, mean (s.d.) ${ }^{3}$ & $92.5(12.1)$ & $99.6(16.6)$ & 0.01 \\
\hline
\end{tabular}

I. DUI $\leqslant 104$ weeks: $n=25$; DUI >104 weeks: $n=27$.

2. DUI $\leqslant 104$ weeks: $n=19 ; \mathrm{DUI}>104$ weeks: $n=23$

3. DUI $\leqslant 104$ weeks: $n=16$; DUI $>104$ weeks: $n=20$.

\section{Response to medication}

Brenner scale scores (Brenner et al, 1990) were available for 48 of the patients in the sample. These showed that following the administration of antipsychotic medication, 24 patients $(50 \%)$ had shown complete clinical remission while $16(33 \%)$ had shown partial remission. Seven $(15 \%)$ patients demonstrated either a slight or moderate degree of resistance to treatment, with the remaining case $(2 \%)$ showing severe resistance. The ratings of response to first exposure to antipsychotic medication were not significantly different between the short and long DUP groups $(t=-0.7, P=0.5)$. But the patients in the long DUI group responded less well than the patients in the short DUI group: their mean Brenner score was higher $(2.1$, s.d. $=1.2$, and 1.6 , s.d. $=0.9$, respectively), at a trend level $(t=-1.9, P=0.07)$.

\section{Social variables}

At the time of admission almost threequarters $(73 \%)$ of the patients in the sample were living with a family member or a partner, while $21 \%$ were living alone and $6 \%$ were homeless. Table 1 gives the numbers of patients in each of these categories in the short and long DUP groups, and shows that a higher proportion of the latter were living alone or homeless $\left(\chi^{2}(1)=3.19\right.$, $P=0.07)$. The respective figures for the short and long DUI groups were very similar, but not statistically significant.

With regard to employment during the previous year, two-thirds $(66 \%)$ of the total sample had mostly been unemployed. Only $13 \%$ (seven patients) had been in steady employment (full-time paid work in five cases and part-time in the other two), while $21 \%$ (11 patients) were students. Table 1 gives the number of patients in each of these categories in the short and long DUP groups, showing that a smaller proportion of the latter were employed or students $\left(\chi^{2}(1)=3.38\right.$, $P=0.07)$. Comparing the short and long DUI groups, the differences were in the same direction but more marked. In the short DUI group, 13 patients were employed or students and 12 were unemployed, while the respective figures for the long DUI group were four and $23\left(\chi^{2}(1)=8.16, P=0.004\right)$.

\section{DISCUSSION}

\section{Clinical correlates of DUP and DUI}

The evidence from previous first-episode studies of schizophrenia (Crow et al, 1986; Loebel et al, 1992; Szymanski et al, 
1995) suggests that a longer period of unchecked, untreated illness in schizophrenia is associated with a poorer prognosis. However, in the present study, those patients with a longer DUP or DUI showed little evidence of any factor that might mediate a poor outcome: specifically, they showed no evidence of a greater worsening of the illness, more severe negative symptoms, more severe positive symptoms, or a greater deterioration in IQ over the initial untreated period. Neither DUP nor DUI showed any significant association with performance on eye movement tasks, or neurocognitive tasks testing memory.

The evidence for a relationship between length of untreated illness and the development of any resistance to antipsychotic medication at first exposure was equivocal. There was a tendency for longer DUI to be associated with a lower level of remission following drug treatment, but there was no association between DUP and response to medication. These findings fail to replicate those of Loebel et al (1992), who found that a longer DUP in first-episode schizophrenia patients predicted both a longer time to remission and a lower level of remission. This disparity cannot be explained on the basis of a difference in length of untreated psychosis between the two samples of patients, as the mean DUP in the Loebel et al study ( 52 weeks) was similar to that in the present study (59 weeks). These figures represent a relatively short average DUP, as the average figure has previously been estimated at 1 to 2 years (Johnstone et al, 1986; Beiser et al, 1993; Häfner et al, 1993), and a recent study of first-episode schizophrenia by Larsen et al (1998) reported a mean DUP of 130 weeks.

One positive finding emerged in respect of executive function. At a trend level, patients in the long DUP group (although not those in the long DUI group) experienced problems with a specific executive function task - shifting attentional setthat could not be explained in terms of a global intellectual deficit. The patients with a long DUP were less likely to complete the task, and more likely to make errors, than those in the short DUP group. Difficulty with the set-shifting task suggests an impaired ability to form abstract concepts based on perceptual dimensions. This failure to 'learn set' and generalise what has been previously learned may contribute to poorer social problem-solving and adaptive functioning in the community (Goldberg $e t$ al, 1995; Addington \& Addington, 1999).
Those patients with a longer DUP were significantly older than those with a short DUP, but this did not reflect an earlier age of onset in the former group. There was no significant difference between the two groups in age of onset of illness, a variable with recognised prognostic significance. This suggests that the correlates of a longer DUP reported here, specifically those related to a poorer performance on the set-shifting task, are not confounded by age of onset. Aside from age, there were few obvious clinical differences between those individuals who, at the time of first presentation, had had untreated schizophrenia for a long time, and those who had had it for a relatively short time, except that the latter were likely to be younger. In that these findings reveal no obvious evidence of progressive deterioration with a longer period of unchecked psychosis, they provide little support for the notion of an underlying active morbid process in the early stages of the schizophrenic illness before antipsychotic medication is first administered. The only evidence in support of such a view was the finding that impairment relating to a particular neurocognitive function - set-shifting ability was more likely to be present after the first 6 months of the psychotic illness, dated from the first manifestation of positive symptoms. However, the extent to which this deficit of executive function reflects deterioration over the period of untreated psychosis is a matter for speculation, as is the extent to which such a deficit might reliably predict long-term social and occupational functioning.

\section{Delay in presentation to clinical services}

An alternative way to view these data is to postulate that any differences between the long and short DUP and long and short DUI groups could reflect delay in identification of the illness, and thus a later presentation to psychiatric services. For example, it has been suggested that the association between a longer period of untreated schizophrenic illness and worse outcomes can be explained in terms of subtypes of the illness (Crow et al, 1986). According to this view, the characteristics of illnesses with an inherently poor prognosis may be such that the illness will tend to be detected at a relatively late stage. Thus, such illnesses might present predominantly with negative symptoms, few florid positive symptoms and little in the way of socially obtrusive behaviour. Such a notion is supported by recent findings of an association between longer DUP and higher scores for negative symptoms in first-episode patients with schizophrenia at first admission to hospital (Binder et al, 1998; Haas et al, 1998; Larsen et al, 1998). However, the present study found no relationships between DUP and DUI and any particular symptom profile, and this argues against the notion of a role for symptomatology in the later identification of the illness, although data were not available to address the possible relevance of aberrant social behaviour.

A further factor relevant to the timing of first presentation to psychiatric services may be global intellectual function, at least for patients with a less abrupt onset of psychotic symptoms. Those patients with a longer DUI had a higher mean current full-scale IQ, and a higher NART-estimated IQ than those with a shorter DUI, although this was not the case when comparing longer and shorter DUP groups. One interpretation of these data is that those patients with a higher IQ are better able to rationalise and explain their psychotic experiences and any related behavioural disturbance, both to themselves and to others. They may also be more capable socially, particularly at preserving supportive relationships. In simple terms, such patients may cope relatively well with the initial development of the illness, and therefore be less likely to manifest the socially disruptive behaviour or florid psychotic disturbance that might cause the illness to be recognised.

Another possible explanation for the association between a longer period of untreated schizophrenia and poor clinical outcome is that social variables associated with a poor prognosis might also delay detection of the illness. Where this issue has been addressed in first-episode studies, the findings have not been consistent. For example, Haas et al (1998) found that the overall premorbid functioning in those individuals who received no antipsychotic medication for a year or more was actually superior to that of those who received such medication earlier. However, Verdoux et al (1998) found that factors such as low educational level and poor global adjustment in the preceding year independently predicted a delay of 3 months or more between the onset of psychotic symptoms and admission to hospital, and these findings led them to suggest that the observed relationship between longer duration of untreated psychosis and poor outcome may be confounded, at least in part, by social variables such as low educational level and low 
socio-economic status. Although we only assessed a limited number of social variables, our findings are in accord with this notion. Those individuals who had been experiencing psychotic symptoms for 26 weeks or longer before presentation to psychiatric services were, at a trend level, more likely to have been unemployed in the year before admission, and living alone or homeless at the time of admission.

\section{ACKNOWLEDGEMENTS}

We thank Leslie-Jane Duncan and lan Cuthbert for their help in administering the neuropsychological tests.

\section{REFERENCES}

Addington, J. \& Addington, D. (1999) Neurocognitive and social functioning in schizophrenia. Schizophrenia Bulletin, 25, 173-182.

American Psychiatric Association (1994) Diagnostic and Statistical Manual of Mental Disorders (4th edn) (DSM-IV). Washington, DC: APA

Andreasen, N. (1990) Methods for assessing positive and negative symptoms. In Schizophrenia: Positive and Negative Symptoms and Syndromes. Modern Problems in Pharmacopsychiatry, vol 24 (ed. N. Andreasen), pp. 73-85. Basel: Karger.

Asberg, M., Montgomery, S. A., Perris, C., et al (1978) The comprehensive psychopathological rating scale. Acto Psychiatrica Scandinavica Supplementum, 27I, 5-27.

Beiser, M., Erickson, D., Fleming, J. A. E., et al (1993) Establishing the onset of psychotic illness. American Journal of Psychiatry, 150, 1349-1345.

Binder, J., Albus, M., Hubmann, W., et al (1998) Neuropsychological impairment and psychopathology in first-episode schizophrenic patients related to the early course of illness. European Archives of Psychiatry \& Clinical Neuroscience, 248, 70-77.

Brenner, H. D., Dencker, S. J., Goldstein, M. J., et al (1990) Defining treatment refractoriness in schizophrenia. Schizophrenia Bulletin, 16, 55I-56I.

Crow, T. J., MacMillan, J. F., Johnson, A. L., et al (1986) Northwick Park study of first episodes of schizophrenia. II. A randomised controlled trial of prophylactic neuroleptic treatment. British Journal of Psychiatry, 148, 120-127.

Goldberg, T. E., Torray, E. F., Gold, J. M., et al (1995) Risk of cognitive impairment in monozygotic twins concordant and discordant for schizophrenia. Schizophrenia Research, I7, 77-84.

Gur, R. E., Mozley, P. D., Resnick, S. M., et al (1991) Relations among clinical scales in schizophrenia. American Journal of Psychiatry, 148, 472-478.

Haas, G. L., Garratt, L. S. \& Sweeney, J. A. (1998) Delay to first antipsychotic medication in schizophrenia: impact on symptomatology and clinical course of illness. Journal of Psychiatric Research, 32, 15I-159.

Häfner, H., Maurer, K., Löffler, W., et al (1993) The influence of age and sex on the onset and early course of schizophrenia. British Journal of Psychiatry, 162, 80-86.

Hutton, S. B., Puri, B. K., Duncan, L.-J., et al (1998a) Executive function in first-episode schizophrenia. Psychological Medicine, 28, 463-473.

\section{CLINICAL IMPLICATIONS}

- The lack of convincing evidence for a progressive deterioration in severity during the initial period of untreated psychosis (if replicated in further studies) weakens the rationale for early intervention strategies in schizophrenia aimed at reduction of symptom severity or resistance to treatment.

- The neurocognitive deficits associated with a longer period of untreated psychosis may be relatively specific impairments of aspects of executive function.

- A relevant measure of the success of early treatment intervention in schizophrenia may be the prevention of deterioration in neurocognitive function. Such interventions may need to occur within the first 6 months after the onset of positive symptoms if they are to be successful.

\section{LIMITATIONS}

- The estimates of the duration of psychotic symptoms and any preceding behavioural and personality changes constituting a prodrome were retrospective.

- Only two social variables were examined, and no behavioural variables.

- The sample was relatively small.

THOMAS R. E. BARNES, FRCPsych, S. B. HUTTON, DPhil, M. J. CHAPMAN, MRCPsych, S. MUTSATSA, MSc, B. K. PURI, MRCPsych, EILEEN M. JOYCE, FRCPsych, Department of Psychiatry, Imperial College School of Medicine, London

Correspondence: Thomas Barnes, Department of Psychiatry, Division of Neuroscience and Psychological Medicine, Imperial College School of Medicine, St Dunstan's Road, London W6 8RF, UK

(First received 9 August 1999, final revision 20 January 2000, accepted 21 January 2000)

_ , Crawford, T. J., Puri, B. K., et al (1998b) Smooth pursuit and saccadic abnormalities in first-episode schizophrenia. Psychological Medicine, 28, 685-692.

Johnstone, E. C., Crow, T. J., Johnson, A. L., et al (1986) The Northwick Park study of first episodes of schizophrenia: I. Presentation of the illness and problems relating to admission. British Journal of Psychiatry, $\mathbf{1 4 8}$ 115-120.

_, McMillan, F. J., Frith, C. D., et al (1990) Further investigation of the predictors of outcome following first schizophrenic episodes. British Journal of Psychiatry, I57, 182-189.

Larsen, T. K., Johannessen, J. O. \& Opjordsmoen, S. (1998) First-episode schizophrenia with long duration of untreated psychosis. Pathways to care. British journal of Psychiatry, 172 (suppl. 33), 45-52.

Liddle, P. F. \& Barnes, T. R. E. (1990) The symptoms of chronic schizophrenia. British Journal of Psychiatry, 157 558-561.

Lieberman, J. A., Jody, D., Geisler, S. H., et al (1993) Time course and biological correlates of treatment response to first episode schizophrenia. Archives of General Psychiatry, 50, 369-376.

Loebel, A. D., Lieberman, J. A., Alvir, J. M., et al (1992) Duration of psychosis and outcome in first-episode schizophrenia. American Journal of Psychiatry, |49, || 83-||88.
McGlashan, T. H. (1998) Early detection and intervention of schizophrenia: rationale and research. British Journal of Psychiatry, 172 (suppl. 33), 3-6.

Nelson, H. E. (1991) The National Adult Reading Test (NART) (2ndversion:Test Manual).Windsor:NFER-Nelson.

Sahakian, B. J. \& Owen, A. M. (1992) Computerised assessment in neuropsychiatry using CANTAB: discussion paper. Journal of the Royal Society of Medicine, 85, 399-402

Shallice, T. (1982) Specific impairments in planning. Philosophical Transactions of the Royal Society of London, Series B: Biological Sciences, 298, 199-209.

Szymanski, S., Lieberman, J. A., Alvir, J. M., et al (1995) Gender differences in onset of illness, treatment response, course and biologic indexes in first-episode schizophrenic patients. American Journal of Psychiatry, 152, 698-703.

Verdoux, H., Bergey, C., Assens, F., et al (1998) Prediction of duration of psychosis before first admission. European Psychiatry, 13, 346-352.

Waddington, J. L., Buckley, P. F., Scully, P. J., et al (1998) Course of psychopathology, cognition and neurobiological abnormality in schizophrenia: developmental origins and amelioration by antipsychotics? Journal of Psychiatric Research, 32, 179-189.

Wechsler, D. (198I) WAIS-R Manual. New York: Psychological Corporation. 